\title{
EARLY MIXING IN BILINGUAL CHILDREN: A PSYCHOLINGUISTICS VIEW
}

\author{
Dwi Ide Rahayu \\ Junior Secondary School 2 of Adimulyo, Kebumen, dwiiderahayu@gmail.com
}

\begin{abstract}
Most studies on Bilinguals First Language Acquisition (BFLA) are concerned with giving explanation for language mixing in young bilinguals. It is commonly stated that language mixing in children has to be interpreted as evidence for confusions in the bilingual's language acquisition, in the sense that the two languages are not acquired separately but start out as a single system. In other words, it is in contrast to adults' code-switching. In this article, early mixing in bilingual children is explored based on psycholinguistics view. This article will first discuss the language acquisition, then the theories and assumptions on bilingualism in early childhood, and last the early mixing in bilingual children. According to the review of related literature, it can be inferred that from psycholinguistics view, language mixing cannot indicate the bilingual children's lack of ability to differentiate the two language system. Spontaneous translation employed by the bilingual children shows that bilingual awareness and language differentiation is possible at an early stage. Bilingual infants can do language mixing as an evidence of their meta-linguistic awareness and language differentiation. As language mixing may be a good indicator of bilingual fluency, we can say that children who become bilingual in their early childhood will reach their fluency in the two languages by doing language mixing according to the two languages they have acquired.
\end{abstract}

Keywords: Language Acquisition, Bilingualism, Early Mixing

Research in bilingualism is concerned with two topics. First, the researches which find appropriate methods of classifying bilinguals and their behaviour with respect to their two languages, in the sense of language choice and language use. Second, in the field of psycholinguistics, the topic is to discover how the two languages are stored in the brain; and whether they are interacting or not.

Furthermore, the acquisition of two languages from birth on is an important topic in the studies of bilingualism. Bilinguals develop two language systems instead of one. Most studies on Bilinguals First Language Acquisition (BFLA) are also concerned with giving explanation for language mixing in young bilinguals. It is commonly stated that language mixing in children has to be interpreted as evidence for confusions in the bilingual's language acquisition, in the sense that the two languages are not acquired separately but start out as a single system. In other words, it is in contrast to adults' code-switching. In this article, early mixing in bilingual children is explored based on psycholinguistics view.

\section{Literature Review \\ Language Acquisition}

There is basic difference between acquisition and learning. Acquisition is a subconscious process that is identical to the process used in first language acquisition in all important ways while learning is conscious knowledge, or "knowing about" language (Krashen, 1989: 8). It can be inferred that while acquisition is taking place, the acquirer is not always aware of it, and he or she is not usually also aware of its results. In contrast to that, when we talk about grammars or rules, we are referring to learning, not acquisition.

In general, there are two main theories on language acquisitions and learning, i.e. behaviourism theory and nativism theory. Below are brief explanations on each.

a. Behaviourism Theory.

This theory is proposed by B.F. Skinner, an expert on psychology. In his books, The Behaviour of Organism (1938) and Verbal Behaviour (1957), he explained that there are two processes on acquiring, i.e. respondent and operant behaviour.

The respondent behaviour is behaviour appeared as a result of certain stimulus. This stimulus will cause automatic responses. The process of stimulus-respondent follows systematic stages. The operant behaviour will occur in certain conditions. If there are reinforcement, either it is in 
the form of reward or punishment, there will be a subsequently responses. In conclusion, it is the environment which plays a big part on someone's language acquisition and learning.

In his theory, Skinner also stated that all human beings who live in a verbal community are a group of people who have the language and be able to 'formulate' their own language so that they can decide which one is correct and which one is incorrect. It can be seen in children; they acquire or learn language from the very simple one to the more complex until they reach their adults. Lexical items are used step by step, again, start from the simplest to the most complicated ones.

b. Nativism Theory

This theory is proposed by Chomsky (1975). The theory is based on assumptions about language faculty of human. According to this theory, the language faculty is genetic. It is a component in human's brain. Intelligence plays the main role in determining the success on acquiring and learning language.

Chomsky then defined what we call as Language Acquisition Devices (LAD). It is believed that this device is owned by every normal baby-born, and has almost the same functions in the first stages of acquisition. This device is very effective in acquisition, yet it is less effective in learning a language.

Saffran et.al. (2001) stated that during the acquisition period, children discover the raw materials in the sounds (or gestures) of their language, learn how they are assembled into longer strings, and map these combinations onto meaning. These processes unfold simultaneously, requiring children to integrate their capacities as they learn, to crack the code of communication that surrounds them. Thus, we can say that the processes of acquisition begin with the phonology acquisition and continued by morphology acquisition, syntactic acquisition, lexicon acquisition, and finished with semantic acquisition.

Hagen (2008) differentiates between L1 acquisition and L2 learning as a consequence of the evolutionary history. He points out some important things related to it.

a. L1 acquisition among children is an astonishing rapid process.

Children have managed to become fluent in a language in the period around three to four years, with virtually no explicit help from parents and peers. On the other hand, it is common to find people who have struggled with a second language for a decade or more without achieving fluency.

b. L1 acquisition is effortless.

Simply exposing children to a linguistically rich environment is enough to ensure fluency. In contrast, people who try to learn second language find the process painstaking, difficult and frustrating.

c. L1 acquisition requires no formal training.

Human languages are governed by highly abstract rules that speakers apply uniformly to utterances. L2 learners often do learn languages via explicit training, and they are generally said to make use from such instructions.

d. Stasis in the case of L1 acquisition is nearly invariable.

All children in all cultures become native speakers; that is, indistinguishable in linguistic grounds from others in their community. Second language learners vary considerable with respect to outcome. While acquiring always achieves native fluency, learners almost never do.

Rice (1989) summarizes the essence of language acquisition. He says that language acquisition entails three components; the language to be acquired, the child and the abilities and predispositions that he or she brings to language acquisition and the environmental setting or the language that the child hears and the speaking context. In a bilingual child case, these processes also happen, both for his or her two languages acquisition.

The main goal in the research field of Bilinguals First Language Acquisition (BFLA) is to prove that language acquisition in a bilingual child is comparable to that of a monolingual child. The difference is, of course, that bilinguals develop two language systems instead of one. The prediction that children do not distinguish the two languages from the beginning has dominated the analyses of bilingual children language development. 
According to all the theories above, it can be inferred that all normal human will reach the acquisition milestones, that are the phonology acquisition and continued by morphology acquisition, syntactic acquisition, lexicon acquisition, and finished with semantic acquisition, either it is in the case of first language acquisition or second language acquisition.

\section{Bilingualism in Early Childhood}

To start the discussion regarding second language acquisition of a bilingual child, the term "bilingualism" must be defined. Brooks (1960) in Taeschner (1983: 5) defines bilingualism as an individual's ability to express himself in a second language, rather than paraphrasing those of his own. Gottardo and Grant (2008) as cited in Summer (2016: 20.1-20.2) says bilingualism as a complex term that is influenced by multiple factors, such as the age of acquisition of the second language, continued exposure to the first language, and the circumstances under which each language is learned. In its simplest form, bilingualism is defined as knowing two languages, it refers to the ability to use two languages in everyday life (Heinlein and Williams, 2013).

A child can become bilingual by simultaneous acquisition or successive acquisition of the second language. A child under the age of 3 who is exposed to two languages usually experiences simultaneous acquisition. If the child is exposed to the second language at an older age, successive acquisition usually occurs (National Center for Research on Cultural Diversity and Second Language Learning, 1995). For the acquisition of a second language, earlier is better (Pettito, 2009).

There are some pros and cons related to early bilingualism. Attitudes against early bilingualism are often based on myths and misinterpretations, rather than scientific findings (Heinlein and Williams, 2013). Some of them say that early bilingualism can cause speech delay. Yet, indeed there are more advantages that could be achieved by promoting early bilingualism associated to early acquisition of a second language. Early acquisition of a second language influences the development of language abilities and cognitive functions (Watterndof et.al, 2014).

Despite the popularity of bilingualism, surprisingly little research has been conducted on the topic, particularly on the foundations of bilingual language learning in infants and toddlers. The science of bilingualism is a young field, and definitive answers to many questions are not yet available. Furthermore, other questions are impossible to answer due to vast differences across families, communities, and cultures. But with an accumulation of research studies over the last few decades, we are now equipped to partially answer some of parents' most pressing questions about early bilingualism. Below are some questions related to early bilingualism and some relevance explanations on each.

a. Are bilingual children confused?

One misunderstood behaviour which is often taken as evidence for confusion, is when bilingual children mix words from two languages in the same sentence. This is known as code mixing. In fact, code mixing is a normal part of bilingual development, and bilingual children actually have good reasons to code mix (Pearson, 2008: 150). Rather than being a sign of confusion, code mixing can be seen as a path of least resistance: a sign of bilingual children's ingenuity.

Infants are sensitive to the perceptual differences between two languages, and are particularly attuned to a language's rhythm. Infants can discriminate rhythmically dissimilar languages like English and French at birth (Byers-Heinlein, Burns, \& Werker, 2010), and by age 4 months they can tell even rhythmically similar languages like French and Spanish apart (Bosch \& SebastiánGallés, 2001). Bilingual infants may be even more sensitive than monolinguals when it comes to discriminating languages. Instead of being confused, it seems that bilingual infants are sensitive to information that distinguishes their languages.

b. Does bilingualism make children smarter?

So far, bilingual cognitive advantages have only been demonstrated using highly sensitive laboratory-based methods, and it is not known whether they play a role in everyday life. Thus, the reported advantages do not imply that bilingualism is an essential ingredient for successful development.

c. Is it best for each person to speak only one language with a bilingual child?

It is still important to consider what strategies families can use to promote early bilingual development. Parents should use whatever strategy promotes high-quality and high-quantity 
exposure to each of their child's languages. This could include structured approaches such as using different languages as a function of person (one-person-one-language), place (one language at home, one language outside), or time (alternating days of the week, or mornings/afternoons). Some parents insist on speaking only one language with their child, even if they are able to speak the other, to ensure exposure to a particular language. Other families find that flexible use of the two languages, without fixed rules, leads to balanced exposure and positive interactions. Each family should consider the language proficiency of each family member as well as their language preference, in conjunction with their community situation. Families should regularly make an objective appraisal of what their child is actually hearing on a daily basis (rather than what they wish their child was hearing), and consider adjusting language use when necessary.

d. Should parents avoid mixing language together?

It is important to note that considerations of code mixing also have important social implications. In some communities, code mixing is an important part of being bilingual and being part of a bilingual community. For example, code mixing is the norm in some Spanish-English communities in the U.S., and Afrikaans-English code mixing is the norm in some parts of South Africa. Different communities have different patterns of and rules for code mixing and children need exposure to these patterns in order to learn them. Bilinguals are able to cope with code mixing from an early age. It has also been suggested that while code mixing might make word learning initially difficult, it is possible that practice switching back and forth between the languages leads to later cognitive benefits (Byers-Heinlein, 2013).

e. Is earlier better?

Applied to bilingualism, the maturational and environmental differences between younger and older learners indicate that it is most advantageous to learn two languages early on in life. Bilinguals who learn two languages from birth are referred to as simultaneous bilinguals, and those who learn a first language followed by a second language are referred to as sequential bilinguals (Heinlein and Williams, 2013). The evidence points to advantages for simultaneous bilinguals relative to sequential bilinguals. They tend to have better accents, more diversified vocabulary, higher grammatical proficiency, and greater skill in real-time language processing.

The messages about bilingual language exposure are clear: more is better, and earlier is better. If you are 60 years old and you have always wanted to learn Japanese, start now. Language learning becomes more challenging with time, for both maturational and environmental reasons, but for those who are motivated (Gardner \& Lambert, 1959), it is never too late to learn a new language.

f. Are bilingual children more likely to have language difficulties, delays, or disorders?

Science has revealed an important property of early bilingual children's language knowledge that might explain this misperception: while bilingual children typically know fewer words in each of their languages than do monolingual learners of those languages, this apparent difference disappears when you calculate bilingual children's "conceptual vocabulary" across both languages (Marchman et al., 2010). That is, if you add together known words in each language, and then make sure you don't double-count cross-language synonyms (e.g., dog and anjing), then bilingual children know approximately the same number of words as monolingual children (Pearson \& Fernández, 1994). In other words, if we measure bilinguals using a monolingual measure, we are more likely to find false evidence of delay. Researchers and clinicians are now developing bilingual-specific measures that paint a more accurate picture of bilinguals' global language competence.

Early bilingualism can be assumed as early two or more languages acquisition. A general terminology of bilingual acquisition could be the 'simultaneous acquisition of more than one language during the period of primary language development' (Genesee, 1989:162). This term implies that both languages must be seen as a first language, hence stating a simultaneous acquisition. It has been proposed to regard acquisition as simultaneous as long as it takes place up to age 3 . If a language is acquired later than this, one has to talk about successive acquisition (Cantone, 2007: 3-4).

In conclusion, it is needed to reshape our views of early bilingualism: children are born ready to learn the language or languages of their environments without confusion or delay. To promote successful 
bilingual development, parents raising bilingual children should ensure that their children have more than enough opportunities to hear and speak both of their languages. As children get older, interacting with monolingual speakers (especially other children) is important for motivating ongoing language use, especially for minority languages not widely spoken in the community (Pearson, 2008).

It is also important to recognize that early childhood is also a time of profound emotional, social, physical, and cognitive development. Bilingualism will be a priority or even a necessity for some families. Other families might choose to focus on other aspects of development. In some cases, where families are not fluent in a second language, early bilingualism might be unrealistic. Here, it is important to keep two things in mind: 1) bilingualism is only one way to promote successful early development, and 2) second language learning is possible at any age. It is better for parents to provide plenty of input and interaction in a language they are comfortable in, than to hold back because they are not fluent or comfortable in the language.

\section{Early Mixing in Bilingual Children}

As discussed earlier, mixing is a commonly happened phenomenon in bilingualism, including in the situation of early bilingualism. The general term 'language mixing' is also used when referring to this phenomenon. Language mixing means when a word of language A or an utterance which contains elements from languages A and B is mixed into the language context of language B. The term 'early mixing' states that we are dealing with language mixing at an early stage of language acquisition (Cantone, 2007: 13).

Most of studies on language mixing try to explain mixing in young bilinguals by referring to a lack of either of three competences, pragmatic competence, lexical competence, or grammatical competence. A lack of pragmatic competence, it is in the sense that children are not yet capable of separating languages with respect to the interlocutor. Second, it is the absence of lexical competence, meaning they do not know the word in one language and therefore use the equivalent word in the other language. Then a lack grammatical competence, that is, the children will use certain structures which have already been acquired in one language in the other language.

One thing that we should keep in our mind is that early mixing in bilingual children is different to adult mixing in the way that early bilingual children acquire both the two language while adult acquire only one language and then learn the other language. What is thought to distinguish bilingual children's mixing from adult mixing is the lack of systematically or compliance to linguistic rules in the case of the children (Sridhar and Sridhar, 1980). Since grammar develops in children, structural rules will not be applicable at an early stage of language acquisition. For this reason, language mixing either follows no rules, or it depends on rules which are different from those adult mixing.

Early bilingual experience in doing language mixing could in theory thereby encourage greater cognitive flexibility, through the greater use of the self-regulatory functions of language (Peal and Lambert, 1962). Diaz (1983) pointed out, however, that this involves various assumptions: (1) that bilingual children are thinking verbally in performing non-verbal tasks; (2) that they switch from one language to another while performing these tasks; and (3) that the habit of switching improves performance. It seems likely that an environment where mixing is common would reinforce the sense of contrast and encourage this process further. Sinka (2000) who studied children's mixing between two typologically very different languages, Latvian and English, considered that the different nature of the two languages enabled the children to separate the two systems at an early stage and to produce language-specific structures. Accordingly, the mixing observed was mainly lexical. Various studies have shown that bilingual children have an enhanced ability, compared with monolinguals, to deal with abstract concepts, which, it is thought, may be a by-product of the early necessity to separate the signifier and the signified (Hamers and Blanc, 2000).

Most studies have shown that only a certain type of words, namely, the so-called function words, are mixed to a high extent, whereas later mixing can occur at any boundary. The question whether early mixing underlies the same grammatical constraints as adult code-switching has been answered by assuming that some kind of proto-grammar rules early utterances in child language, also affecting mixing, in the sense that language mixing in child language might be analyzed differently from adult mixing (Cantone, 2007: 34). As soon as grammar begins to mature, and functional categories emerge, a 
qualitative change in mixing might show up. A further explanation for mixing is language dominance, a phenomenon that can come to the fore in terms of a bigger lexicon in one of the two languages. Early mixing is then due to the lack of the appropriate word in the so-called Weaker Language (WL). Another outcome of language dominance is mixing within the syntax. Along these lines, the less developed language will profit from the more developed one. A third type of dominance refers to specific grammatical properties of the two languages involved.

In investigating language mixing, mechanisms for keeping languages separate are one important focus. If languages in the bilingual brain were totally separate, neither translation nor mixing would be possible; if they were totally integrated, then bilinguals would presumably code-switch and code-mix randomly all the time and would not be able to speak monolingually. The question used to be asked in terms of whether there was one "lexical store" or "mental lexicon" in the bilingual brain or two. Much research has now shown that bilinguals can never totally "switch off" one of their languages, and the question is now asked in different terms: how does the bilingual "access" words from their different languages appropriately for the task in hand? Whereas many studies throw light on how this is done at the level of perception - since input can be manipulated experimentally - very little is yet known about production, since it cannot be manipulated in the same way (de Bot, 2004).

Meuter (2005) suggests that the available evidence on activation on mental lexicon indicates that all related lexical representations are activated late in the selection process, and that there are four main types of internal factors relevant to the selection of a language:

(1) global "de-selection" of the undesired language, though we cannot be sure the de-selection is global or whether it only affects the relevant parts;

(2) the effect of proficiency: it has been shown in various experimental tasks that it is more difficult to inhibit the L1 than the L2, but that once that has been done switching back into the L1 takes longer than continuing in the L2 (as measured in milliseconds);

(3) the factors that trigger a switch or a mix;

(4) the monitoring capacity, which allows the selected language to be maintained.

These processes are obviously largely subconscious, as speakers are on the whole not very aware of their code-switching behaviour, and tend to be surprised at their own performance if you play it back to them.

Specifically in early mixing in bilingual children, some external factors should also be taken into account; that are the language input or the language use in the family, the specific language context, and the interlocutor. It is indeed proven that language use in the family, and particularly among the interlocutors who were recorded, can have an impact on how the children behaved with respect to language choice and use (Cantone, 2007: 110).

In the literature on early mixing, the distinction between different categories of mixed elements has been used in order to discriminate two different qualitative stages of mixing (Köppe \& Meisel 1995 in Cantone 2007: 128). In the early stage, it has been stated that a certain class of words is mixed, namely the so-called function words, whereas in a later stage of language mixing all categories can be found among the mixed words. The children mix a restricted class of words, namely, deictic elements, adverbials, particles, numerals, affirmatives/negatives, nouns, adjectives, and verbs. A type/token analysis also confirms that only a limited number of items are mixed (Cantone, 2007: 156).

\section{Conclusion}

Based on the review of some theories on language acquisition, bilingualism in early childhood, and early mixing in bilingual children above, it can be inferred that from psycholinguistics view, language mixing cannot indicate the bilingual children's lack of ability to differentiate the two language system. Spontaneous translation employed by the bilingual children show that bilingual awareness and language differentiation is possible at an early stage. Bilingual infants can do language mixing as an evidence of their meta-linguistic awareness and language differentiation. As language mixing may be a good indicator of bilingual fluency, we can say that children who become bilingual in their early childhood will reach their fluency in the two languages by doing language mixing according to the the two languages they have acquired.

\section{References}


Bosch, L., \& Sebastián-Gallés, N. (2001). Evidence of early language discrimination abilities in infants from bilingual environments. Infancy, Vol. 2 No. 1, 29-49.

Byers-Heinlein, K., Burns, T. C., \& Werker, J. F. (2010). The roots of bilingualism in new-borns. Psychological Science, Vol. 21 No. 3, 343-348.

Byers-Heinlein, K \& Williams, C. L. (2013). Bilingualism in the early years: what the science says. Learning landscapes, Vol. 7, No.1, 95-112.

Byers-Heinlein, K., Fennell, C.T., \& Werker, J.F. (2013). The development of associative word learning in monolingual and bilingual infants. Bilingualism: language and cognition, Vol. 16, No. 1, 198205.

Cantone, K. F. (2007). Code-switching in bilingual children. Dordrecht: Springer.

De Bot, K. (2004). The multilingual lexicon: modelling selection and control. International journal of multilingualism, Vol. 1, No. 1, 17-32.

Diaz, R.M. (1983). Thought in two languages: the impact of bilingualism on cognitive development. Review of research in education. Vol. , E.W. Gordon (ed.). Washington, DC: AERA.

Gardner, R. C., \& Lambert, W. E. (1959). Motivational variables in second language acquisition. Canadian journal of psychology, Vol. 13, No. 4, 266-272.

Genesee, F. (1989). Early bilingual development: one language or two? Journal of child language, Vol. $16,161-179$.

Hagen, L.K. (2008). The bilingual brain: human evolution and second language acquisition. Evolutionary Psychology, Vol. 6, 43-63.

Hamers, J. and Blanc, M.H.A. (2000). Bilinguality and bilingualism, 2nd ed. Cambridge: Cambridge University Press.

Krashen, S. D. (1989). Language acquisition and language education: extensions and application. London: BPCC Wheatons Ltd.

Marchman, V. A., Fernald, A., \& Hurtado, N. (2010). How vocabulary size in two languages relates to efficiency in spoken word recognition by young Spanish-English bilinguals. Journal of child language, Vol. 37, No. 4, 817-840.

McLaughlin, B. (1995). Fostering second language development in young children. National Center for Research on Cultural Diversity and Second Language Learning. Retrieved December, 29, 2016, 10.26 a.m, from http://www.cal.org/resource-center/briefs-digests/digests/(offset)/30.

Meuter, R. F. I. (2005). Language selection in bilinguals: mechanisms and processes. The Handbook of Bilingualism: psycholinguistic approaches, J. F. Kroll \& A.M. B. de Groot (eds). Oxford: Oxford University Press, 349-370.

Peal, E. and Lambert, W. (1962). The relationship of bilingualism to intelligence. Psychological monographs Vol. 76, 1-23.

Pearson, B. Z., \& Fernández, S. C. (1994). Patterns of interaction in the lexical growth in two languages of bilingual infants and toddlers. Language learning, Vol. 44, No. 4, 617-653. 
Pearson, B. Z. (2008). Raising a bilingual child. New York: Random House.

Petitto, L. A. (2009). New discoveries from the bilingual brain and mind across the life span: implications for education. International mind, brain, and education society and Blackwell Publishing, Inc. Vol. 3, 185-197.

Rice, M. L. (1989). Children's language acquisition. American psychologist Vol. 44, 149-156.

Saffran, J.R., Senghas, A., \& Trueswell, J. C. (2001). The acquisition of language by children. PNAS, Vol. 98 No. 23.

Sinka, I. (2000). The search for cross-linguistic influences in the language of young Latvian-English bilinguals. Döpke, 2000, 149-175.

Skinner, B. F. (1938). The behavior of organisms: an experimental analysis. New York, London: D. Appleton-Century Company, Incorporated.

Skinner, B. F. (1957). Verbal behavior. New York: Appleton-Century-Crofts.

Sridhar, S. N. \& Sridhar, K. K. (1980). The syntax and psycholinguistics of bilingual code switching. Canadian journal of psychology, Vol. 34, 407-416.

Summer, L. Q. (2016). Language acquisition for the bilingual child: a perspective on raising bilingual children in the U. S. National Center for Hearing and Management (NCHM) ebook, chapter 20, 20.1-20.12. Utah: Utah State University.

Taeschner, T. (1983). The sun is feminine: A study on language acquisition in bilingual children. Berlin: Springer-Verlag.

Watterndorf, E, et.al. (2014). Early bilingualism influences early and subsequently later acquired languages in cortical regions representing control functions. International Journal of Bilingualism, Vol. 18, 48-66. 